\title{
Palliative Care: Theory, Research, and Treatment in the English-speaking Caribbean Region
}

\author{
ME Sutherland
}

\begin{abstract}
Background: The English-speaking Caribbean (ESC) region is experiencing an epidemic of chronic communicable and non-communicable diseases that increases the likelihood of morbidity and mortality-related outcomes, resulting in lower life expectancies for both young and old individuals. In resource-poor ESC countries, economically challenged patients have inadequate access to analgesic drugs and experience unnecessarily painful deaths. This paper addresses the theory and research on the assumptions and benefits of high-quality palliative care.

Objectives: This paper reviews the evidence regarding the difficulties encountered by patients and their relatives when dealing with chronic and terminal illnesses. These include: the inadequacies of the public and private hospitals throughout the ESC countries, and the high financial cost to patients and their relatives in accessing medical care.

Results: The possible barriers accounting for the underdevelopment of palliative care in this region are discussed. They include: cultural beliefs on the aetiology of diseases, pain management, and on herbal treatment of chronic and terminal diseases, restrictive regulatory drug statutes and the dearth of specialized palliative care providers in the ESC countries.

Conclusion: This paper offers recommendations for the development of sustainable, efficient, high-quality, and culturally relevant palliative care services throughout the ESC region. National guidelines and policies are needed on the standards of care, and on pain assessment and symptom and pain management. Well-trained palliative community health-workers and volunteers are recommended. The need for the ESC governments to prioritize the delivery of palliative care by integrating palliative care and hospice care services in the national public health systems is addressed.
\end{abstract}

Keywords: High-quality care, home-based care, pain management, palliative care

\section{Cuidados Paliativos: Teoría, Investigación y Tratamiento en la Región del Caribe Anglófono}

\author{
ME Sutherland
}

\section{RESUMEN}

Antecedentes: La región del Caribe Anglófono (CAF) está experimentando una epidemia de enfermedades crónicas y enfermedades no transmisibles que aumentan la probabilidad de

From: University at Albany, Departments of Africana Studies and Psychology, 1400 Washington Avenue, BA 115, Albany, New York, 12222

West Indian Med J 2017; 66 (6): 715
Correspondence: Dr ME Sutherland, University at Albany Departments of Africana Studies and Psychology, 1400 Washington Avenue, BA 115, Albany, New York, 1222. Email: ms781@albany. edu 
morbilidad y resultados relacionados con la mortalidad, lo que resulta en una expectativa de vida más baja para los individuos jóvenes y ancianos. En los países del CAF, pobres en recursos, los pacientes con problemas económicos tienen acceso inadecuado a fármacos analgésicos y experimentan muertes innecesariamente dolorosas. Este documento aborda la teoría y la investigación sobre los principios y beneficios del cuidado paliativo de alta calidad.

Objetivos: Este articulo examina las evidencias relativas a las dificultades encontradas por los pacientes y sus familiares al tratar con las enfermedades crónicas y terminales. Estas dificultades incluyen: insuficiencias de los hospitales públicos y privados en los países de CAF, y el alto costo financiero que los pacientes y sus familiares enfrentan para tener acceso a la atención médica.

Resultados: Se discuten las posibles barreras que causan el subdesarrollo de la atención paliativa en esta región. Estas incluyen: las creencias culturales sobre la etiología de las enfermedades, el manejo del dolor, el tratamiento herbario de enfermedades crónicas y terminales, los estatus sobre regulación y restricción de los medicamentos, y la escasez de proveedores especializados en cuidados paliativos en los países de CAF.

Conclusión: Este artículo ofrece recomendaciones para el desarrollo de servicios de cuidados paliativos sostenibles, eficientes, de alta calidad, y culturalmente relativos en toda la región del CAF. Las pautas y las políticas nacionales son necesarias para las normas y políticas en relación con los estándares del cuidado paliativo, la evaluación del dolor, y el manejo de los sintomas y el dolor. Se recomiendan trabajadores de la salud comunitarios y voluntarios bien entrenados en cuidados paliativos. Se aborda la necesidad de que los gobiernos del CAF den prioridad a la prestación de cuidados paliativos mediante la integración de los servicios de cuidados paliativos con los de hospitales para enfermos terminales en los sistemas nacionales de salud pública.

Palabras clave: Cuidado de alta calidad, cuidado en el hogar, manejo del dolor, cuidados paliativos

West Indian Med J 2017; 66 (6): 716

\section{INTRODUCTION}

Many people, including young and old people, living in the English-speaking Caribbean (ESC) countries experience chronic and terminal illnesses that contribute to high mortality, including breast, cervical, ovarian, prostate, colorectal, lung, stomach, liver, and other cancers; cardiovascular diseases; hypertension; diabetes mellitus; HIV/AIDS; renal failure; chronic respiratory diseases; injuries and violence; diseases associated with ageing; and other causes $(1,2)$. Likewise, there is a general agreement that an epidemic of chronic non-communicable diseases accounts for nearly half of the deaths of people younger than 70 years (3). Approximately $60 \%$ of older people in the ESC region reportedly have at least one chronic disease. Moreover, older, poorer and depressed women are at an increased risk of dying from chronic diseases (4).

Cancer is the third leading cause of death in the ESC countries, following cardiovascular and cerebrovascular diseases (5). The ESC countries, including Jamaica,
Barbados, and the Bahamas, have the highest age-standardized prostate cancer mortality rates in the world (6); there are also high mortality rates from breast and cervical cancers in Caribbean women $(5,7)$. Most cancers, as well as other non-communicable and communicable diseases, in the ESC countries are identified after the occurrence of their symptoms and signs, which increases the likelihood of morbidity- and mortality-related outcomes for advanced metastatic diseases (6) and the end stage of other diseases (8).

There is evidence regarding the heavy financial and emotional burdens of economically-challenged Caribbean individuals who are chronically and terminally ill (6). In resource-poor ESC countries, most terminally ill patients, who experience severe pain and distressing symptoms do not have access to appropriate analgesic drugs and other medications and they cannot afford to purchase pain relief medications (9). There is also a financial burden relating to invasive medical interventions such as radiology, urological radiotherapy, 
cardiopulmonary resuscitation and other medical treatments (6). Seriously ill patients and their relatives may also be concerned about the multiple medical interventions that can leave them confused, distressed, and preoccupied about the future and financial costs of further medical interventions. In the absence of effective palliative care and curative care systems to appropriately address the needs of patients and their families living in the ESC countries $(8,10)$, most patients and their relatives experience undue hardships and severe financial and psychosocial strains when dealing with chronic and terminal illnesses (11).

The ESC countries include 15 relatively small countries and the two larger continental countries of Belize and Guyana. This article describes the status of palliative care in these ESC countries. The relationship between seriously ill and dying Caribbean patients and the healthcare system is also discussed. The present theory and research regarding palliative care and hospice care are presented. Finally, recommendations for the development of high-quality and culturally appropriate palliative services throughout the ESC countries are discussed.

\section{Response to life-threatening illnesses in the ESC countries}

Many qualitative studies have indicated that, in the event of life-threatening illnesses, the majority of Caribbean people prefer to die at home rather than in hospitals. Despite the challenges, some individuals' self-reports indicate better care at home than in the hospital $(12,13)$. This might be related to the inadequacies of the public and private hospitals and medical centres throughout the ESC countries. The excessive financial costs for the diagnoses and treatment are also barriers to accessing healthcare. Lower-income chronically and terminally ill Caribbean patients are reportedly treated unequally by healthcare providers. In addition, family members experience fear and uncertainty regarding the patients' medical condition and treatment (13). Nurses have refused to deliver pain medications such as morphine, codeine and other opioids to hospitalized patients (12). This reluctance is said to be related to misguided beliefs that these are illicit, dangerous, and addictive narcotics and to cultural beliefs that pain and suffering are destined by God; therefore, one can manage or tolerate such pain. Other individuals might believe that little or nothing can be done for their pain and suffering, or they are afraid of taking medications (14). The financial costs of purchasing adequate pain medications might also be unaffordable for many patients and their relatives. Hence, many chronically and terminally ill Caribbean patients experience unrelenting pain, without adequate pain medications and unnecessarily painful deaths $(11,15-17)$.

In the absence of palliative care, pain relief and counselling, terminally ill Caribbean patients who receive home care tend to rely on prayers and spiritual comfort in accordance with the dominant Christian religion of the Caribbean. The factors associated with reliance on traditional herbal medicine, traditional healers, or family and community support include a general lack of information regarding conventional medicine, indigenous cultural beliefs about the aetiology of illnesses such as cancer is a curse and therefore a spiritual malady and Christian beliefs about the use of herbs for healing/ medicinal purposes $(9,13)$.

Reports indicate that terminally ill Caribbean patients, who choose to die at their homes, experience severe physical and emotional pains. For instance, it is not unusual for public and private hospitals and pharmacies not to stock pain medications or to refuse to provide them to patients (11). The affected families are typically without financial support, counselling, training, and home-care assistance in the small and resource-limited communities in the ESC countries, which are characterized by a paucity of healthcare resources $(11,13)$.

In a qualitative study, family members reported that patients who died at home were in comfortable and familiar settings (12). They were cared for and provided with their own food preferences, and family members and close friends attended to their personal care. However, there can be relational problems, a sense of disempowerment, and psychological distress experienced by seriously ill patients and their relatives. Emotional distress can exacerbate the patients' symptoms, among other adverse psychosocial and physical outcomes. Studies indicate that providing long-term care for seriously ill relatives can compromise the overall physical, psychosocial, and spiritual health of caregivers who are subsequently at risk for depression, cardiovascular disease, compromised immune function and increased mortality (18). Therefore, research studies are needed regarding the nature and quality of family relations in the context of caring for seriously ill family members in Caribbean home settings, as well as the overall impact on caregivers. Similarly, evidence-based data are needed regarding the patients' perceptions of family caregivers and their responses to family care services. Data are required on the degree of attachment, intimacy, hours of 
contact between patients and caregivers, and anticipatory grief of both patients and relatives (18).

\section{Theory of and research on palliative care}

Palliative care services and hospice care are some of the most neglected aspects of the care of chronically and terminally ill Caribbean patients, especially for vulnerable patients with the least financial and educational resources. There are also limited hospice care facilities and home-based hospice care services throughout the ESC countries. In addition, paediatric palliative care is an underdeveloped public health area.

Both palliative and hospice care emphasize quality of life issues for patients and families dealing with chronic and life-threatening illnesses. Hospice care is related to the patient being terminally ill and agreeing to a purely palliative approach. Therefore, hospice care involves symptom and pain control and medical, psychological, spiritual and family support. This approach is guided by a quality of life assumption, that is, to assist individuals to die in peace and comfort and with dignity (10).

It is generally agreed that the quality of life concerns for affected patients and their families are of particular importance when facing life-threatening illnesses and throughout the trajectory of chronic illnesses. Palliative care has been defined as the provision of care from the beginning of the trajectory of life-threatening or lifelimiting illnesses to alleviate physical, psychosocial, and spiritual suffering and to enhance the quality of life for patients and their families. Other aims include: the careful assessment of the delivery of services, delivery of conventional medicine, prevention and control of pain and other distressing symptoms, and the delivery of comprehensive, multidisciplinary support to the patient and family throughout the course of the illness $(10,19)$. Palliative care and curative-medical treatments are typically delivered concurrently. Palliative care is essential for the prevention of debilitating illnesses and for the provision of supportive services to assist patients and their relatives to cope with chronic and terminal illnesses.

Palliative care provides practical assistance with medical/nursing concerns such as assisting patients and their relatives in negotiating the medical system, treatment for mental distress, depression, and anxiety and counselling to assist the patients' emotions, loss and grief.

Relatives are provided with support during the bereavement period. Family caregivers are provided respite care to ease the burden of caring for dying relatives. Therefore, effective palliative care is a multidisciplinary and person-centred approach concerned with the quality of life issues related to the end-of-life and bereavement (15).

Palliative care can be provided by teams, nurse/nurse practitioners, doctors, social workers, chaplains, psychologists, community health-workers, ordinary caring people and community volunteers. The aim is to create and sustain "communities of care" for the delivery of high-quality palliative care (20). The team approach is essential for home care, hospitals, nursing homes, longterm care institutions and other places of care (13). This team model is useful for the ESC countries, with the inclusion of healthcare practitioners, healthcare officials, family caregivers, pharmacists, psychologists, local policy-makers, community leaders and external experts in the field of palliative care. To accomplish these goals, Kasl-Godley, King and Quill (19) stated that team members should have "some knowledge of the basic pathophysiology of common diseases and the symptoms experienced by palliative care patients $(e g$, pain, fatigue, nausea, dyspnoea, insomnia, wasting syndromes, delirium and constipation) and should become familiar with the physical changes common to active dying (eg, changes in breathing, urine output, circulation, terminal delirium" (p. 367).

Palliative care can be delivered in hospital settings, medical centres, outpatient clinics, home-care settings, long-term care facilities and community medical centres (19). Palliative care services can better prepare patients and their families to effectively cope with the course of the disease to the terminal stage. Effective palliative care can engender positive emotions and a sense of well-being as well as feelings of gratitude, compassion, forgiveness, spiritual comfort, and emotional and spiritual growth despite the difficulties of dealing with life-threatening illnesses. Other studies show that individuals who receive palliative care are more likely, than those who receive usual care, to report better pain control and symptom management and less likely to experience repeated hospital visits (21). Based on the weight of the existing evidence, it is cost-effective and humane for the ESC governments to prioritize the delivery of palliative care by integrating palliative care and hospice care services into the national public health systems.

\section{Communication and palliative care}

Communication earlier in the trajectory of an illness is purported to have positive effects on patients' satisfaction and their choices. According to Smith, Davis and Krakauer (22), communication and relational skills are 
essential components of high-quality care for terminally ill patients. Communication with patients and their relatives about their goals as well as the goals of palliative care should be compassionate, direct, honest, and open, with genuine sensitivity and trust. Patients should be educated about their illness and prognosis. Healthcare practitioners should discuss what can and cannot be done at the terminal stage of the disease trajectory, while also being attentive to supporting and promoting the patients' well-being. Palliative care practitioners should actively listen to the responses of patients and their family members and be able to appropriately manage their own affective responses. Consistent with the person-centred orientation, when conducting end-of-life discussions with patients and their relatives about treatment options, including treatment withdrawal, it is essential that practitioners be guided by the premise that patients have the right to identify their palliative care preferences and that the treatment of symptoms should be based on the patient's needs.

According to Kasl-Godley, King and Quill (19), good communication can influence patients' adherence to treatment regimens, the rate of recovery, patients' satisfaction with care, and pain control and can improve the psychological functioning of patients and their family members. The evidence suggests that patients, who experience effective palliative care and hospice care, report that their exposure to the relevant information allowed them to feel more confident in making informed decisions. Consequently, they feel less distressed (19). In contrast, poor communication is related to dissatisfaction and increased co-morbidity of cancer patients and their family caregivers (15).

Patients with terminal illnesses may experience a sense of hopelessness and regret at not being able to accomplish certain life goals. They may be concerned about unresolved life issues as well as other spiritual and existential issues. Healthcare practitioners should provide the opportunity for the patients and their family members to explore these issues with the aim of gaining greater clarity and acceptance of the inevitability of the end and should assist the patients and their relatives to consider living fully in the midst of suffering. It has been suggested that there is a positive relationship between a patient's suffering and the caregiver's distress. Hence, the control of the patient's pain, depression, spiritual distress and psychosocial strain could contribute to improved well-being for the caregiver. Such improvements can also help to address the caregiver's distressing concerns (18).
Palliative care is also concerned with the quality of patient-physician relationships to ensure that the patient is an active and self-determining agent in decision-making regarding their end-of-life treatment preferences. Manalo (23) described the need to "individualize care option discussions to illness status, and patient and family preferences, beliefs, values, and cultures. The process of shared decision-making between the patient, the family and the clinicians should continue as goals evolve and change over time" (p.1). The main focus of care delivery is based on the patient's and their relatives' needs and wishes. The perspectives of patients, their relatives, and health professionals should inform how services are organized and delivered throughout the ESC countries. Likewise, culturally relevant and socio-economically appropriate palliative and hospice care services should be developed for adults and children who are chronically ill and dying in these countries (12).

\section{Improving palliative care in the ESC Countries}

Caribbean nations and institutions appear to lack written policies on effective pain relief and end-of-life care (13). There is a paucity of regional and national information on palliative care, hospice care, and home care. National guidelines that highlight the standards of care for chronic and dying patients are needed. Reliable evidence is required regarding national and local health policies and guidelines on healthcare proxy, living wills, do-notresuscitate (DNR) directives, healthcare practitioners' discussions with family and patients about end-of-life care, and medical interventions (22).

Pain management is a significant pressing need for patients who are at the terminal stage of their illnesses. There is an urgent need to address the barriers to pain medications for chronically and terminally ill Caribbean patients. The major barriers appear to be restrictive regulatory statutes and misinformation and misguided beliefs about the misuse and misappropriation of opioids and other essential palliative medications (14). Caribbean governments should review and revise the regulatory laws to facilitate the delivery of pain and other palliative medications for medical and scientific use. It is imperative that Caribbean governments establish a system of controls to prevent the abuse and diversion of opioid analgesics.

There are also deficits in the public and private healthcare systems, including high medical costs and the lack of attention regarding the development of pain management priorities (12). Governmental policies on pain assessment and pain management are needed. 
Policy remedies are required for the perceived barriers to caring for poor and vulnerable ESC patients, including long waiting lines, patient anxiety about the nature and quality of medical services, lack of funds to cover transportation costs for medical purposes, and the negative attitudes of medical practitioners (12).

Caribbean healthcare providers could benefit from appropriate training on effectively managing chronically ill and dying patients and their families. For instance, Jamaican patients and families report mistrust and poor communication when dealing with healthcare practitioners. Other communication problems include: inaccessible language used by physicians in the delivery of medical information, feelings of being disrespected and patronized by healthcare personnel, very long waiting times to be seen by medical staff, and the lack of information and assistance in offsetting the cost of medications (11). Caribbean palliative care teams have the responsibility to challenge the cultural myths and misperceptions of the aetiology of illnesses by sharing basic knowledge on the aetiology and trajectory of illnesses. Palliative practitioners will need to address the depression, fear of death and isolation reported by caregivers of Caribbean cancer patients (11).

It also appears that the knowledge of physicians and other health-workers regarding palliative care needs to be improved, particularly regarding pain assessment and pain and symptom management skills for the effective delivery of pain medications and appropriate management of patient care. Mental health personnel, including psychologists and psychiatrists, should be central to the team approach to palliative care in the ESC countries. There is sufficient evidence of the high levels of depressive symptoms and anxiety in seriously ill patients and their family caregivers (24). Across the ESC region, there are varying rates of depression among patients with diabetes, cancer patients, the elderly, the financially challenged, and individuals and family caregivers dealing with chronic and terminal diseases. Women are more likely to have higher levels of depression and anxiety than men, and these psychological co-morbidities of these psychological disturbances with existing diseases must be addressed by the palliative care personnel (25).

In brief, Caribbean healthcare workers and governmental officials should strive to provide integrated and holistic palliative care to patients with chronic and terminal diseases to improve the overall quality of life for the patients and their families (26). Macpherson (12) advised collaboration among medical and supportive services in achieving high-quality palliative care for the
ESC patients and their relatives. The networks of healthcare personnel, national policy-makers, community leaders, and other major health and political stakeholders are better able to institute and evaluate optimal care and identify the best practices (15). It is generally agreed that these objectives are more achievable when palliative care services are integrated with the national public health system (10).

There is a dearth in the ESC countries of specialist palliative care providers with extensive training in this field, with appropriate credentials and working in this field. For instance, a disproportionate number of Caribbean surgeons do not have adequate training in minimally invasive surgery, primarily due to the lack of operating room time, lack of equipment, and paucity of surgeons with advanced credentials to mentor medical students (27). There are only a few hospice or palliative care facilities and palliative specialists throughout the ESC countries (14). Similarly, there is inadequate information from the ESC countries on the availability of specialty drugs that are effective in treating chronic illnesses such as cancers and HIV/AIDS and that can assist patients with living longer and healthier lives. It is essential to underscore that specialist palliative care is more effective than conventional care (15).

Paediatric palliative care is a neglected area of research in the ESC countries. A significant number of Caribbean children and young adults die each year from cancers, HIV/AIDS, neonatal assaults, chronic kidney disease, and other chronic and terminal diseases (28-30). There are very few published studies conducted in the ESC countries regarding this topic. Bodkyn and Lalchandani (28) published the first comprehensive population-based findings regarding the incidence of childhood cancer in Trinidad and Tobago. The issues discussed for adult palliative and hospice care, personcentred care, the control and management of pain and distress, and attention to the patients' mental, psychosocial, emotional, and spiritual well-being also apply to the treatment of chronically and terminally ill children. There must be special care given to the cognitive and emotional life of children facing life-threatening illnesses. Palliative care practitioners should address the emotional responses of parents, siblings and other close relatives of dying children (30).

Children may have difficulty in describing the severity of their symptoms and pain to healthcare practitioners. The research literature describes many measures and approaches to appropriately and effectively address such concerns (10). Scholars, civil 
society, medical practitioners, and other essential healthcare and policy-making personnel should prioritize paediatric palliative care.

Considerably more palliative care providers are needed in the ESC countries. Nursing and medical training programmes should provide specialized training in paediatric and adult palliative care, hospice care and home-based care. Institutions of higher learning, including The University of the West Indies (UWI) campuses, should provide degree-granting training to undergraduate and graduate students for paediatric and adult palliative care and hospice care. The graduates of these programmes should emerge as strong advocates of paediatric and adult palliative and hospice care throughout the ESC countries.

There is a shortage of qualified health-workers in the Caribbean. Therefore, attention should be directed at trained community health-workers and volunteers in the provision of palliative care. The community level provides an essential source of support, particularly in rural communities. A distance-learning component for the practice of palliative care would be accessible to healthcare professionals in the rural areas (20).

Collaboration between community health-workers and medical and other supportive services is required to achieve high-quality palliative care in the ESC countries. Such care requires the maintenance of regular contact with each other and the adoption of system-wide standards of care (20). Mobile healthcare clinics and government mandated media announcements regarding the usefulness of palliative care are also recommended (11). For instance, the Caribbean public should be made aware that patients with terminal diseases can have access to both traditional medical treatment of their diseases and palliative care for their disease. According to experimental research findings, compared with conventional medical treatment only, the early integration of palliative care with standard oncologic treatment in advanced lung cancer patients results in a longer life span of approximately two months, improvements in patients' mood, and less expensive, less invasive medical treatment in the final months of life (31).

For the successful implementation of palliative care throughout the ESC countries, the following deficiencies should be remedied. There are limited regional and national data on cancer morbidity and mortality. A few of the ESC countries such as Jamaica, Trinidad and Tobago, have cancer registries. However, the reported data are restricted to certain communities; therefore, nationwide data are lacking (1). There are insufficient national and regional guidelines and mechanisms that provide guidance for health institutions to evaluate the quality of care or track the progress towards institutional and national priorities. The ESC countries have not established computer-based linkages within and between the data sources of the various health institutions (1). Consequently, it is not yet possible to effectively monitor the morbidity and mortality of patients. Regional data for disease screening, treatment of life-threatening illnesses and aspects of pain evaluation are needed. The existing guidelines for the treatment of chronic and terminal diseases should be adequately disseminated. Evidence-based regional and national data are needed regarding who is eligible for palliative care.

\section{CONCLUSION}

In conclusion, non-communicable and communicable diseases are expensive in both human and economic terms. The treatment of these diseases poses serious threats to the economic structure of the ESC countries, including both financial expenditure and labour costs from the significant number of patients and their relatives coping with chronic and life-threatening diseases who are therefore missing from the workforce. For instance, the total healthcare cost, expressed as a percentage of the gross domestic product, for the treatment of hypertension and diabetes ranged from $0.5 \%$ in the Bahamas to $5.2 \%$ in Trinidad and Tobago (32). There are additional costs for the training of medical and non-medical staff, particularly in the context of a scarce national budget. This article also highlighted other deficiencies in the Caribbean healthcare systems. As previously noted, palliative care reduces the financial burden on healthcare spending by minimizing patients' exposure to unnecessary medical treatments and reducing the length of hospital stays. Hence, the Caribbean governments are challenged to issue national guidelines for the implementation of cost-saving, highquality, and culturally-relevant palliative care, hospice care, home care, and paediatric palliative care for adults, children, and their relatives dealing with chronic and terminal illnesses.

\section{Declaration of conflicting interests}

The author declares no potential conflicts of interest with respect to the research, authorship, and/or publication of this article.

\section{Funding}

The author received no financial support for the research, authorship, and/or publication of this article. 


\section{REFERENCES}

1. Ferguson TS, Tulloch-Reid MK, Cunningham-Myrie CA. Chronic disease in the Caribbean: strategies to respond to the public health challenge in the region. What can we learn from Jamaica's experience? West Indian Med J 2011; 60: 397-411.

2. Dallaire F, Dewailly E, Rouja P. Cancer incidence and mortality rates in Bermuda. West Indian Med J 2009; 58: 367-74.

3. Morris E, Unwin N, Ali E, Brathwaite-Graham L, Samuels TA. Chronic non-communicable disease risk factor survey 2010 among University of the West Indies staff at Cave Hill, Barbados. West Indian Med J 2011; 60: $452-58$

4. Gibson RC, Neita SM, Abel WD, James K, Eldemire-Shearer D. Sociodemographic factors associated with depressive symptoms among elderly persons from two communities in Kingston, Jamaica. West Indian Med J 2013; 62: 615-19.

5. Phillips AA, Jacobson JS, Magai C, Consedine N, Horowicz-Mehler NC, Neugut AI. Cancer incidence and mortality in the Caribbean. Cancer Invest 2007; 25: 476-483.

6. Aiken WD, Eldemire-Shearer D. Prostrate cancer in Jamaica and the wider Caribbean: it is time to consider screening. West Indian Med J 2012; 61: 90-93.

7. Pierce Campbell CM, Curado MP, Harlow SD, Soliman AS. Variation in cervical cancer incidence in Latin America and the Caribbean. Rev Panam Salud Public 2012; 31: 492-98.

8. Soyibo AK, Roberts, L, Barton EN. Chronic kidney disease in the Caribbean. West Indian Med J 2011; 60: 464-70.

9. Spence D, Merriman A, Binagwaho A. Palliative care in Africa and the Caribbean. PLoS Med 2004; 1:e5.

10. World Health Organization Global atlas of palliative care at the end of life. 2014. Available from: http://www.thewhpca.org/resources/globalatlas-on-end-of-life-care. Accessed July 14, 2014.

11. Spence D, Crath R, Hibbert A, Phillips-Jackson K, Barillas A, Castagnier $\mathrm{T}$ et al. Supporting cancer patients in Jamaica - a needs assessment survey. West Indian Med J 2010; 59: 59-66.

12. Macpherson CC. Healthcare development requires stakeholder consultation: palliative care in the Caribbean. Camb Q Healthc Ethics 2006; 15: $248-255$.

13. Kreitzschitz S, Macpherson CC. End of life care. Perspectives from families and caregivers. West Indian Med J 2003; 52: 311-16.

14. Macpherson CC, Chiochankitmum N, Akpinar-Elci M. Hospice and palliation in the English-speaking Caribbean. Camb Q Healthc Ethics 2014; 23: $341-48$.

15. Jocham HR, Dassen T, Widdershoven G, Halfens R. Evaluating palliative care - a review of the literature. Palliat Care 2009; 3: 5-12.

16. Aarons D. Cancer: the best way to die? January 18, 2015. Available from: http://www.jamaicaobserver.com/news/Cancer--The-best-way-todie_18229067. Accessed January 20, 2015.
17. Cammock-Gayle M. Melody Cammock-Gayle: Cold, callous care at University Hospital. July 4, 2015. Available from: http:/jjamaicagleaner. com/article/commentary/20150704/melody-cammock-gayle-cold-callous-care-university-hospital. Accessed July 5, 2015.

18. Hebert RS, Arnold RM, Schulz R. Improving well-being in caregivers of terminally ill patients. Making the case for patient suffering as a focus for intervention research. J Pain Symptom Manage 2007; 34: 539-46.

19. Kasl-Godley JE, King DA, Quill TE. Opportunities for psychologists in palliative care: working with patients and families across the disease continuum. Am Psychol 2014; 69: 364-76.

20. O'Neill J, Marconi K. Access to palliative care in the USA: why emphasize vulnerable populations? J R Soc Med 2001; 94: 452-57.

21. Edmonds PM, Stuttaford JM, Penny J, Synch AA, Chamberlain J. Do hospital palliative care teams improve symptom control? Use of a modified STAS as an evaluation tool. Palliat Med 1998; 12: 345-51.

22. Smith AK, Davis RB, Krakauer EL. Differences in the quality of the patient-physician relationship among terminally ill African American and white patients: impact on advance care planning and treatment preferences. J Gen Intern Med 2007; 22: 1579-582.

23. Manalo MF. End-of life decisions about withholding or withdrawing therapy: medical, ethnical, and religio-cultural considerations. Palliat Care 2013; 7: 1-5.

24. Changoor TM, Hutchinson G. The prevalence of depressive symptoms in a Trinidadian cardiac population. West Indian Med J 2013; 62: 620-27.

25. Frederick FT, Maharajh HD. Prevalence of depression in type 2 diabetic patients in Trinidad and Tobago. West Indian Med J 2013; 62: 628-31.

26. Kell ME, Walley JD. Palliative care for HIV in the era of antiretroviral therapy availability: perspectives of nurses in Lesotho. BMC Palliat Care 2009; 8: 11.

27. Leake PA, Qureshi A, Plummer J, Okrainec A. Minimally invasive surgery training in the Caribbean - a survey of general surgical residents and their trainers. West Indian Med J 2012; 61: 708-15.

28. Bodkyn C, Lalchandani S. Incidence of childhood cancer in Trinidad and Tobago. West Indian Med J 2010; 59: 465-68.

29. Gibson TN, Hanchard B, Waugh N, McNaughton D. Cancer in adolescents and young adults, Kingston and St. Andrew, Jamaica, 1988-2007. West Indian Med J 2013; 62: 21-27.

30. Lum Lock AL, Bodkyn C, Ali Z. Parent perceptions of paediatric oncology services at the Eric Williams Medical Sciences Complex, Trinidad and Tobago. West Indian Med J 2012, 61: 32-36.

31. Temel JS, Greer JA, Muzikansky A, Gallagher ER, Admane S, Jackson VA et al. Early palliative care for patients with metastatic non-small-cell lung cancer. N Engl J Med 2010; 363: 733-42.

32. Theodore K. Chronic non-communicable diseases and the economy. West Indian Med J 2011; 60: 392-96. 